\title{
FORGOTTEN ARCHITECTURE: SMART TOOLS FOR CULTURAL TOURISM IN THE CLOISTER OF THE PRIOR (SANTA MARIA DELLE GRAZIE, MILAN)
}

\author{
C. Bolognesi ${ }^{1}$, D. Aiello ${ }^{2}$ \\ ${ }^{1}$ Politecnico di Milano, ABC department, 20135 Milano, Italy - cecilia.bolognesi@ polimi.it \\ ${ }^{2}$ Politecnico di Milano, ABC department, 20135 Milano, Italy - damianoaiello@ gmail.com
}

Commission WG II/8

KEY WORDS: Digital Survey, Photogrammetry, Virtual Reality, Augmented Reality, Digital Cultural Heritage

\begin{abstract}
:
This paper describes the relationship among an important nineteenth-century monument, the Cloister of the Prior (located in the convent of Santa Maria delle Grazie, Milan), its survey and the technical integration of different cultural information to be enjoyed in VR and AR during its visit. In this context, the surveying techniques have to face the problem related to the presence of white and smooth surfaces and the difficulty in obtaining a good result in the 3D modelling. Various tests have been performed to create a good point cloud from the photogrammetric survey of the cloister, conducted through the use of different camera lenses or post production interventions applied to the images, in order to obtain the best results. The 3D modelling is not only a base for creating virtual and augmented experiences (that, through digital contents, explain to the distracted public the history of this less known part of the monument) but also a starting point for possible further studies focused on the modifications that affected the cloister over the centuries.
\end{abstract}

\section{INTRODUCTION}

\subsection{Background}

The present paper is written as a contribution to debate on the photogrammetric survey in the field of Cultural Heritage as a tool for historical studies regarding monuments; the point of view of this research considers photogrammetry as an activity that can be practiced by scholars using simple and widespread instruments such as cameras and smartphones, also in lacks of other complex devices.

This is why this study aims first and foremost to experiment the effectiveness and speed of innovative tools for the sfm (structure from motion) photogrammetric survey compared to the traditional ones. In this regard, the use of the fisheye lens has been tested. It has been proved that the fisheye lens can provide excellent results as regards the speed in the survey and the lightness of the photographic dataset, thanks to its wide field of view (FOV). This reduction in the amount of required data can thus accelerate and simplify the photogrammetric process and can make it effective even in surveying surfaces characterized by the lack of significant reference points (such as monochromatic walls) (Perfetti et al., 2017; Perfetti et al., 2018), as is the case of the architecture investigated in this research.

As a second fundamental step, this experimentation explores then VR and AR techniques as a natural integration with the digital survey aimed at deeply knowing a monument.

The methodology of the research assumes the digital survey as the basis for storing and diffusing cultural information concerning sites that are for some reason inaccessible or forgotten. This is what happens in the case study considered: although it is located in a UNESCO site (the convent of Santa Maria delle Grazie in Milan), the influx of visitors is mostly concentrated in other (more famous and iconic) parts of the monument.
The research aims to develop (through a close relationship between the history of the site and the digital models surveyed) some tools (smart and virtual applications) and strategies that are user-friendly for distracted tourists who daily visit the monument.

\subsection{Case study}

The specific case study is focused on the Cloister of the Prior (Fig. 1) in Santa Maria delle Grazie, one of the most important churches in Milan. Built and modified in several phases, with their unique style that combines the Tuscan architectural forms and the taste of Lombard decoration, the church and the adjoining convent are a sign of the historical transition from the Middle Age to the Renaissance and represent one of the highest examples of synthesis between Gothic and Renaissance style.

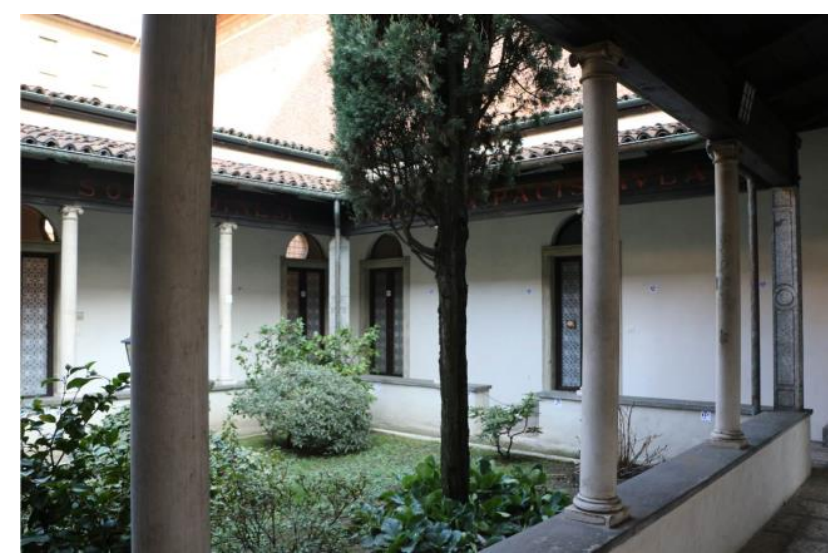

Figure 1. View of the Cloister of the Prior

The convent houses, inter alia, the most famous Leonardo da Vinci's painting, The Last Supper, which is still today one of the most important pictorial masterpieces of all time. 
The complex stands on a parcel of land that Count Gaspare Vimercati, donated in 1460 to the Dominican.

The friars commissioned Guiniforte Solari to design and build a large church and a convent, whose construction started in September 1463 and was completed in 1490.

Shortly after the construction of the church Ludovico il Moro, decreed the enlargement of the building. He had both the apse and the presbytery demolished and started the construction of the magnificent tribune, traditionally attributed to Donato Bramante (even if there is no documentary evidence to confirm this) (Marani et al, 1986).

In the same years in which the tribune was built, two other rooms were erected next to the church: the large sacristy and the Cloister of the Frogs, designed to directly connect the sacristy to the church.

With the fall of Ludovico il Moro (1499) all the construction works ceased.

At the end of the nineteenth century, the entire complex was restored by Luca Beltrami (Martelli G., 1981). During these interventions the small cloister of the Prior was built in NeoRenaissance style, on a previous court, located between the Bramante Sacristy and the Cloister of the Dead and directly connected, through a gate, to the Cloister of the Frogs (Caccin et al, 1983).

On August 15,1943, when the Anglo-American bombers hit the complex, destroying the left side chapels of the church, the Cloister of the Dead, the Library and the Refectory. Only Leonardo's Last Supper and Donato Montorfano's Crucifixion were saved from the destruction (Fig. 2).

The reconstruction of the complex, begun in the post-war period, was only partial.

The entire history of the monument needs of some were partially destroyed by Ludovico il Moro to allow the new Bramante's construction), during the $19^{\text {th }}$ century (when Luca Beltrami brought the religious complex to its Renaissance appearance, restoring the site and shaping the Cloister of the Prior) and, eventually, during the $20^{\text {th }}$ century, because of the damages due to the war.

Studies concerning this complicated history find an effective support in digital surveying, 3D modelling and use of virtual and augmented reality as tools to make people know and understand the complicated evolution of this case study.

\section{RELATED WORKS}

In the perspective of documentation, preservation, dissemination and fruition of cultural heritage, several projects have been developed to find new ways of communicating and enhancing the legacy of the past. The goal of most of these is to bring people into contact with distant and inaccessible realities and to digitally preserve cultural heritage subject to particular risk factors through $3 \mathrm{D}$ databases, in order to transmit it to future generations.

Probably, the most effective tools able to make this goal real are the models and virtual simulations; they guarantee that every generation (present and future) can experience certain places, enjoy their beauty and learn important lessons from them in unconventional ways. This is the principle behind the digitization project of Myin-pya-gu ( $11^{\text {th }}$ century temple located in Bagan, Myanmar) (Dhanda et al., 2019) which is based on the possibility of visiting the ancient temple and getting in touch with its sculptures. More immersive is the "Nefertari: Journey to Eternity" project (Curiosity Stream et al, 2018): it consists in the virtual reconstruction of the tomb of the Egyptian queen, which is no longer accessible to the public in

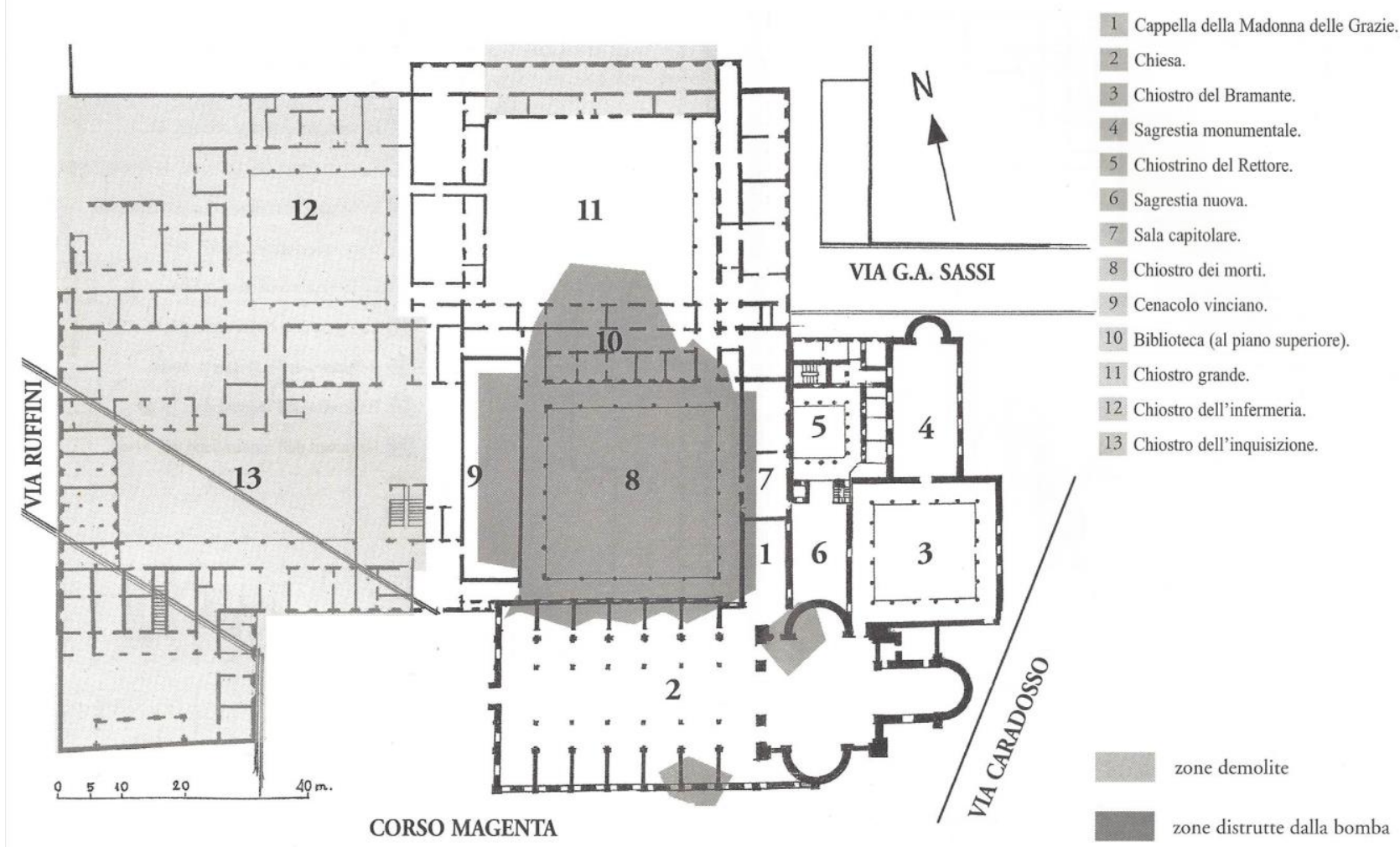

Figure 2. Plan of the convent of Santa Maria delle Grazie showing the parts destroyed during the bombing (Gattico G., 2004) specifications, as it is the result of complicated stratifications that had their peak during the $15^{\text {th }}$ century (when the first order to preserve its precious and delicate pictorial cycles. Here the user has the opportunity to visit every room of the tomb and 
learn the Egyptian history, art and mythology through a series of interactive elements.

Another expressive tool adopted in cultural heritage is augmented reality that makes it possible to see a digital content within a real life scenario. It has allowed many museums to give visitors a more in-depth and unprecedented view of the history and characteristics of the analysed objects.

One of the first institutions to introduce AR in its exhibitions is the Smithsonian's National Museum of Natural History in Washington D.C., which developed the "Skin and Bones" app (Smithsonian Institution, 2015). The application, developed in 2015, available for Apple devices and freely downloadable, allows you to bring to life 13 prehistoric skeletons. Through an interactive menu, the visitor is able to view animated 3D reconstructions in his device (in which the prehistoric specimen is presented in its original appearance) and, at the same time, to obtain information through images and videos.

The Museum of Celtic Heritage in Hallein has developed an app called "The Speaking Celt" (Breuss-Schneeweis, 2016) aimed primarily at younger visitors: by pointing devices at the objects of the collection (specifically indicated by targets), the avatars of two Celts will appear and will lead visitors to discover their civilization.

In Austria, in the archaeological park of Carnuntum (the largest archaeological area in northern Europe), another augmented reality project has been developed (7reasons Medien $\mathrm{GmbH}$, 2018). The app allows us to discover how the site was before, when a gladiator school once was located. The project is based on the creation of a 3D model of the building as it should have appeared in Roman times. This reconstruction can be viewed on any mobile device (through an app downloadable at the beginning of the tour) when you are at the archaeological site.

One of the last cases is the "Viaggi d'Acqua" exhibition (organized by the Carrara Academy of Bergamo), based on the use of smart glasses (ArtGlass, 2017). The AR experience allows us to understand more deeply the artworks, helping us to immerse ourselves in the paintings and to become one with them. Once the glasses are worn, the paintings will come alive and a special earphone will provide information on the works, highlighting the differences in the techniques of water representation between the various authors.

In addition to innovating the way of experiencing the visit within the museum, augmented reality has also found application as means for the re-appropriation of peripheral urban spaces abandoned to decay. In this context, two projects developed in Italy should be analysed.

The MAUA (Bepart et al., 2017) is a rehabilitation project of some Milanese urban suburbs (Giambellino, Lorenteggio, Niguarda, Bovisa) created by both street and digital artists. It consists of animating fifty murals by pointing them with a smartphone.

MoMAR (DoSomethingGood, 2018) follows the same principle: it is an app (designed by a group of independent artists) that uses AR to revive and combine traditional collections such as those of the MoMA in New York (in particular many works by Pollock).

Recent examples of AR application in cultural contexts aimed at enhancing and disseminating cultural heritage are represented by the apps recently developed by two research group. The first one aims at showing the stained-glass design of five Canadian House of Commons windows starting from a 3D printed model (Carrión-Ruiz et al., 2019). Instead, the second one is aimed at the documentation, storage and dissemination of Turin Baroque atria (Palma et al., 2019). The research team is exploring possibilities for recognizing and tracing three-dimensional objects in augmented reality.
Usually, VR and AR projects related to cultural heritage's enhancement and fruition are linked to the serious game's paradigm, linked to the creation of gaming experiences aimed at a playful learning. Serious games for the $\mathrm{CH}$ can help nonspecialized users (such as museum visitors, tourists, students, etc.) to live new experiences and expand their knowledge (Anderson et al., 2010; Candy et al. 2014). There are numerous applications developed in recent years in this context. The Etruscanning project aims at recreating and restoring the original context of the Regolini-Galassi tomb in the necropolis of Sorbo a Cerveteri, reconstructed in 3D along with the objects found in it and exhibited in the Vatican Museums. A key aspect of this project is the development of natural interaction interfaces: visitors use body movements to explore the 3D space and to access digital contents without the need for any traditional interface (Pietroni, 2013). The serious game Via Appia is a system of augmented reality where a kilometre of the ancient Via Appia was reconstructed in three different historical periods. In this way the user can explore the concept of narrative movement by traveling through space and time in a historical site. The app includes quiz games with questions related to information provided by the virtual environment (Liestol, 2014).

\section{DIGITAL PHOTOGRAMMETRIC SURVEY}

The technology chosen for the reconstruction of the digital model of the Cloister of the Prior is photogrammetry. This decision comes from precise reasons, linked to the need to create a virtual experience with a high level of quality. This is why it was essential to reconstruct the material and the chromatic data through a photographic dataset rather than a laser scanner (considering that the quality of the texture obtained from laser scanner is lower than the one obtained through photogrammetry).

Considering this starting point, two photogrammetric tools have been examined: a $18 \mathrm{~mm}$ normal lens and a fisheye lens. These two lenses have been applied to a Canon EOS 70D camera. It was decided to try both lenses to understand which one was more effective in facing the obstacles present in the cloister, mainly related to the white and smooth walls, which do not have particular reference points (small imperfections, chromatic variations, etc.) useful for aligning the photogrammetric dataset. Another obstacle was linked to the limited size of the cloister and to the lack of a good natural lighting because of its orientation (due to which photographic images tend to present excessive contrasts)

The two lenses have different strengths and weaknesses: thanks to its wide field of view, the fisheye lens has the advantage of making it possible to survey with a smaller number of photos than the large number of images that it is usually necessary to acquire when using traditional lenses. An inconvenience in the use of the fisheye is linked to the quality of the images, which decreases radially; this means that, in their peripheral parts, the photos taken with this lens have a relatively low resolution and show visible blurring. This problem is accentuated by the fact that the photogrammetric software used (Metashape) needs to correct the fisheye distortions, producing alterations during the texture creation phase.

On the other hand, despite the disadvantage of acquiring a relatively large photographic dataset, the normal lens has the advantage of taking photos with greater and more uniform quality than the images obtained with fisheye.

Considering that the main challenge in the survey of the Cloister of the Prior is linked, as mentioned, to the reconstruction of the white walls, it was decided first of all to 
test the two lenses on the southern wall, which is the most problematic one, as it has the largest plastered surface.

In this case, the normal lens allowed to take 88 photos of the wall but only 78 of them were aligned. The result was a mesh that presented various imperfections and a certain level of noise. To limit these inconveniences, the 88 photos have been modified by applying filters on Photoshop, in order to highlight the small chromatic differences and the slightest inaccuracies taken in each image (Fig. 3).
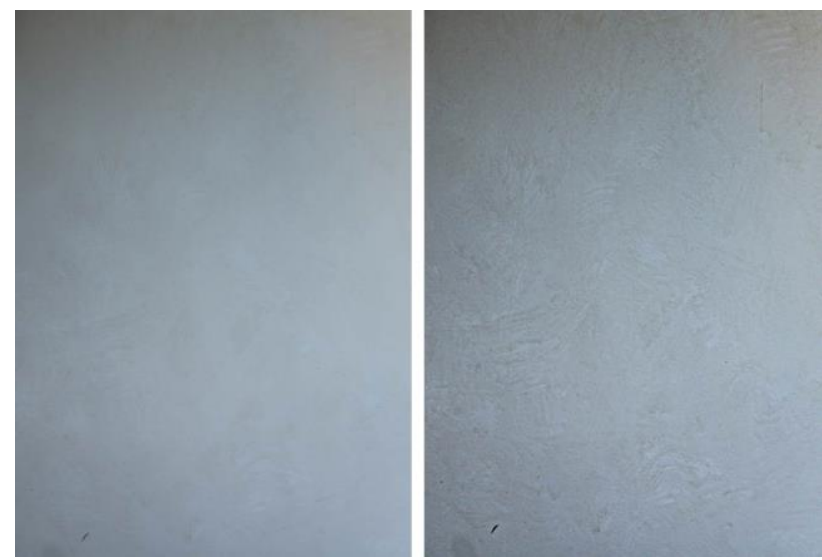

Figure 3. Photo of the plaster of the wall before (left) and after (right) the post-processing on Photoshop

This method allowed to align all 88 photos of the south wall. This expedient therefore facilitated the reconstruction of the model but had the disadvantage of altering the colours of the texture. For this reason, the modified photos were finally used exclusively to construct the geometry of the cloister (its mesh), while the original images (not modified) were used to construct the texture to be applied to the mesh (Fig. 4).
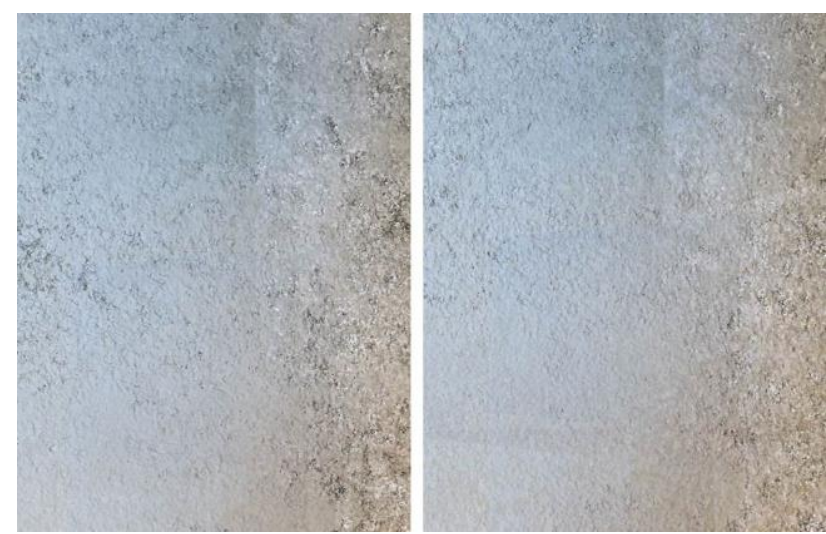

Figure 4. Pointcloud of the white wall (normal lens) before (left) and after (right) the post-processing on Photoshop

Regarding the photos taken with the fisheye, 47 images were enough to cover the extension of the entire south wall. All the photos were aligned at the first attempt (the alignment was facilitated thanks to the width of the field of view captured by the lens). In this first case, however, the resulting point cloud and mesh were characterized by a high level of noise and the texture obtained was not very detailed due to the fisheye radial blur. To solve this problem, two solutions were attempted: the first was to apply a circular mask with the aim of eliminating the entire edge of the photos, thus removing the most blurred parts. This allowed us to improve the texture, even if we didn't succeed in achieving precise and detailed pointcloud and mesh. In order to improve the quality of them, the fisheye images were modified using filters, obtaining a significant improvement (Fig. $5)$.
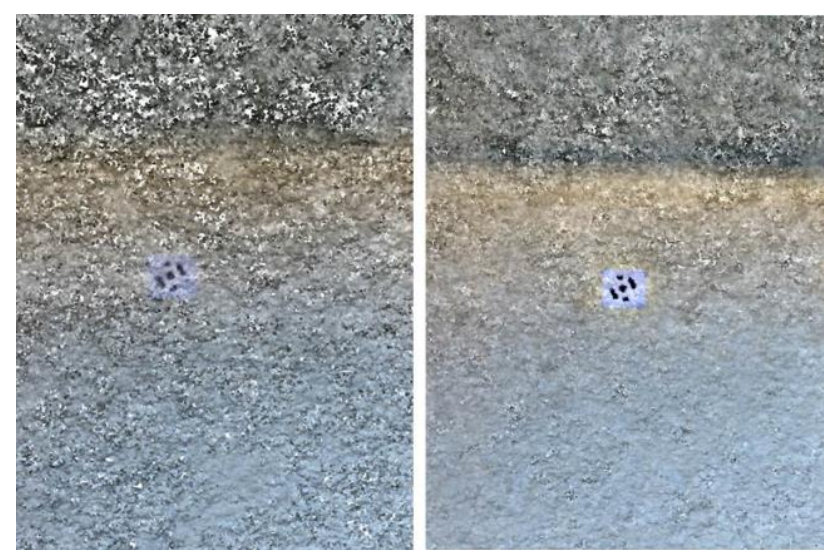

Figure 5. Pointcloud of the white wall (fisheye lens) before (left) and after (right) the post-processing on Photoshop

After having weighed the pros and cons of these two procedures applied only to the southern wall, it was finally decided to reconstruct the digital model of the entire cloister using the photos taken with the normal lens (which provided the best degree of detail).

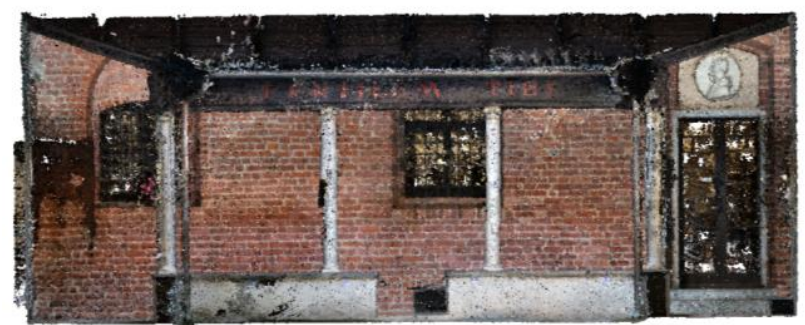

Figure 6. Pointcloud of the western wall of the cloister

Due to various inaccuracies that could not be avoided, it was necessary to integrate the mesh obtained with photogrammetry with various parts modelled as NURBS on Rhinoceros software, using the mesh from photogrammetry as a basis for modelling (in order to guarantee an accurate reconstruction) (Fig. 7).

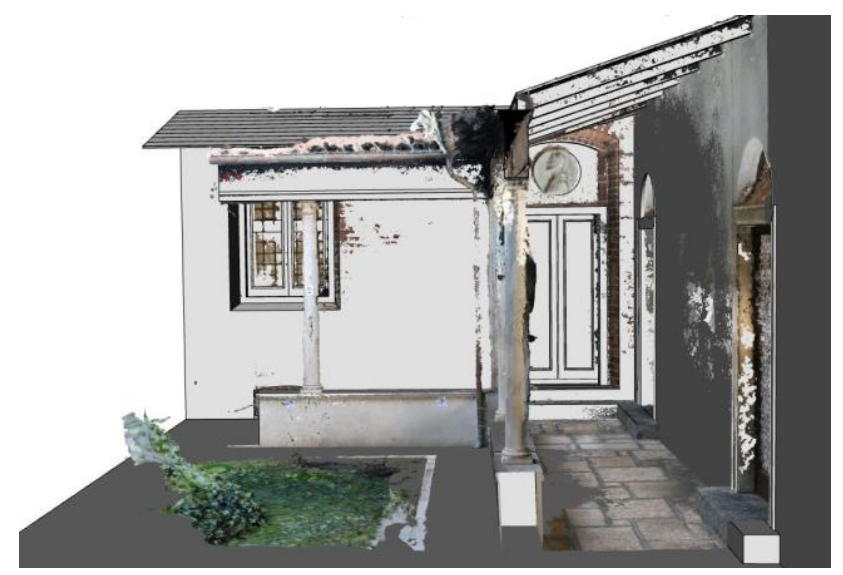

Figure 7. Mathematical reconstruction starting from the mesh

In this regard, it was finally decided not to use the meshes of the white walls, reserving the possibility to improve the survey techniques in future experiments. Finally, the plastered perimeter walls, the doors, the moldings and some parts of the roof were modelled on Rhino. Instead, the capitals, the column 
shafts, the corner pillars, the floor and the brick walls were obtained from photogrammetry (Fig. 8).

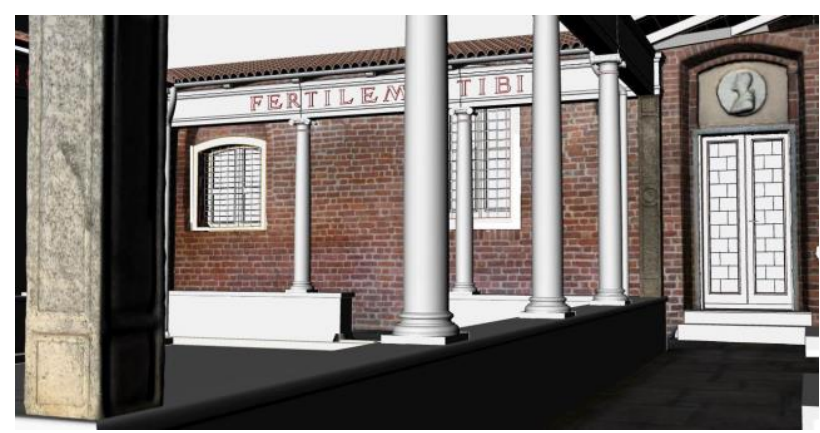

Figure 8. Complete model of the cloister

\section{DIGITIZATION PROJECT}

\subsection{Virtual Reality}

The ultimate goal of this study is the creation of a VR experience aimed at promoting, enhancing and enjoying the Cloister of the Prior. The reason behind this experimentation is linked to the awareness that the case study belongs to the category of the forgotten places of the city, being inaccessible (and reserved for the use of the monks and staff working in the building), despite it represents a very important testimony of the troubled history of the convent of Santa Maria delle Grazie and constitutes a significant example of Luca Beltrami's architectural productions and restoration theories.

The experimentation allows us to revive the cloister as a place of memory, which contains reminiscences of the devastation suffered by the monastic complex during the bombing of 15 August 1943.

The virtual simulation was obtained putting together the mathematical model created on Rhinoceros and the meshes obtained from photogrammetry.

The meshes are extremely complex and consist of too many faces to be managed in virtual reality environments (in terms of rendering times and fluidity) and need to be optimized. For this reason, after detecting and solving the meshes issues on Recap Photo (holes and particles), they were imported into ZBrush, a digital sculpting tool that combines 3D/2.5D modelling, texturing and painting, able to manage millions of polygons at once.

Once imported, the model has been duplicated in two identical clones: the first one is the target model from which the detail information will be cloned, the second one has been subjected to a retopology operation (Palestini et al., 2017). Through this process it was possible to optimize the number of polygonal faces and change their triangular geometry in a quadrangular mesh, more easily manageable. After creating UV maps, the level of detail and the colour information were finally projected from the first target mesh (the original one) to the second retopologized one. The result of this process is a simplified and texturized mesh that simulates the features of the original one without the need to maintain the high level of detail (Aiello et al., 2019) (Fig. 9).
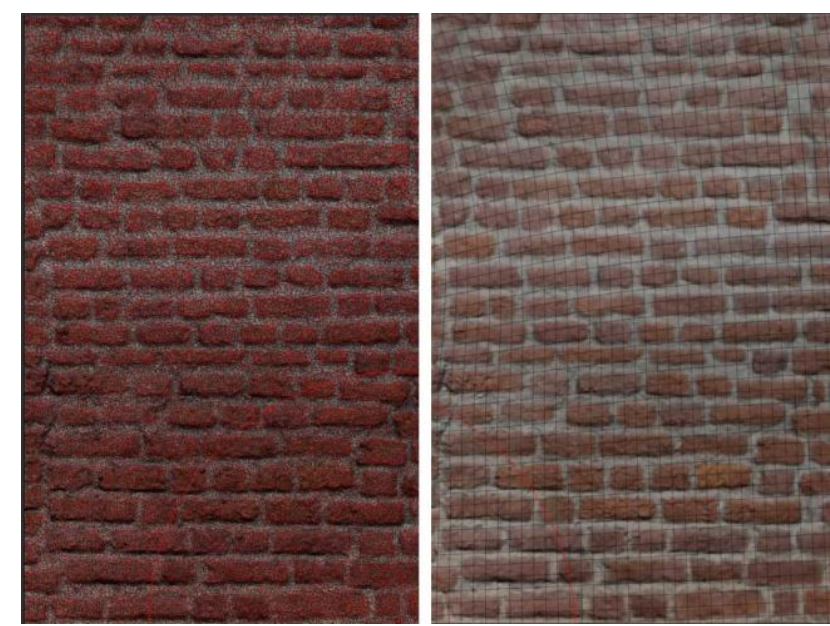

Figure 9. Comparison between the mesh obtained from photogrammetry (left) and the one optimized with ZBrush (right)

The virtual simulation, obtained starting from the import of the model on the gaming software Unreal Engine, consists of a faithful reproduction of the cloister, which can be thus travelled in its entirety and analysed in every architectural detail (Fig. $10)$.

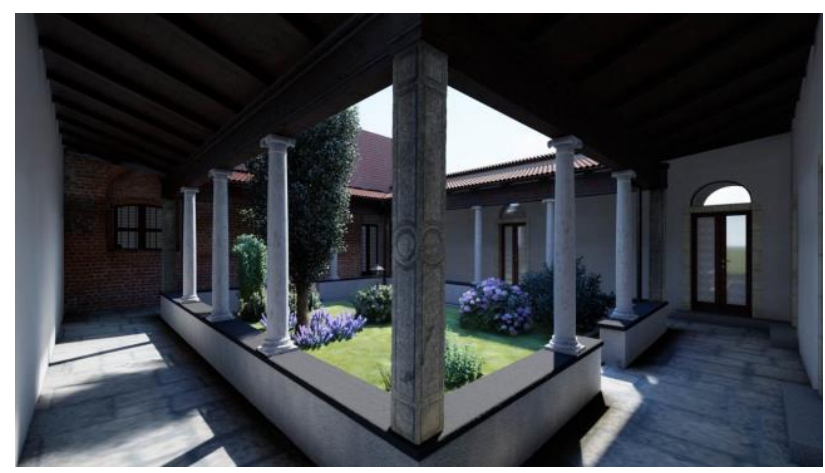

Figure 10. View of the virtual environment

Once inside the virtual environment, the visitor is accompanied by a narrator who tells the history of the cloister, its evolution over the centuries and its relationship with the rest of the monastic complex. During the virtual exploration, a video that retraces the painful page of the bombing of 1943 and that shows, inter alia, the ruins of the convent of Santa Maria delle Grazie, will appear (Fig. 11).

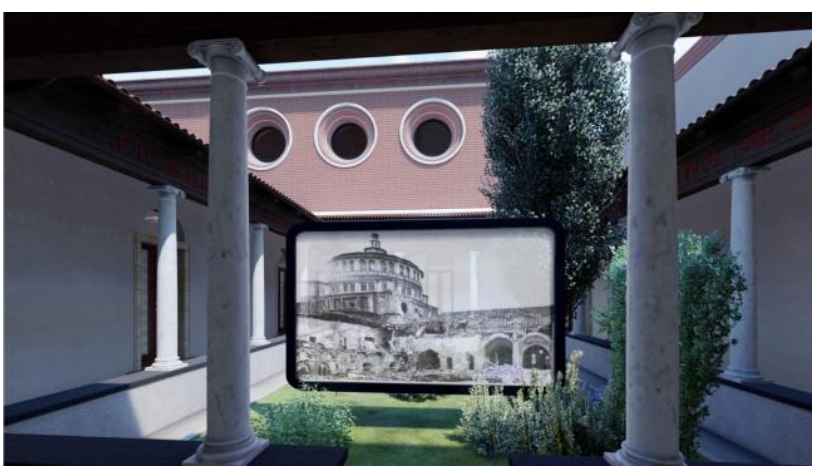

Figure 11. View of the virtual environment. In the centre of the cloister, a video showing the consequences of the bombing of 1943 
The virtual visit experience of the Cloister of the Prior is designed to be extended in the future to the adjacent rooms of the convent (firstly the Cloister of the Frogs and the Sacristy of Bramante), with the aim of creating a single wide visit path and discovering the historical and architectural stratifications of what is certainly one of the most important places in the historic centre of Milan.

\subsection{Augmented Reality}

In addition to the VR experience, a AR application was also proposed, with a view to using it in the perspective of a future opening of the cloister to the public. In this case, the place would be transformed into an important outdoor exhibition, able to transmit knowledge about the history and works of the monastic complex in an unconventional way, through interactive elements to be experienced in situ.

The augmented reality simulation was developed (using Vuforia) as a mobile and tablet app, based on target images placed in the real world. These targets are recognized by the device, that overlaps with them various information and multimedia elements. The latter can be displayed on the device screen by means of virtual buttons, which appear as animated icons and must be activated by pressing them in the real space, where the buttons are virtually placed. Touching these objects, as mentioned, audio-visual multimedia contents (such as documentaries showing the places of the city in the aftermath of the bombing) and various information panels with images and text will appear (Fig. 12).

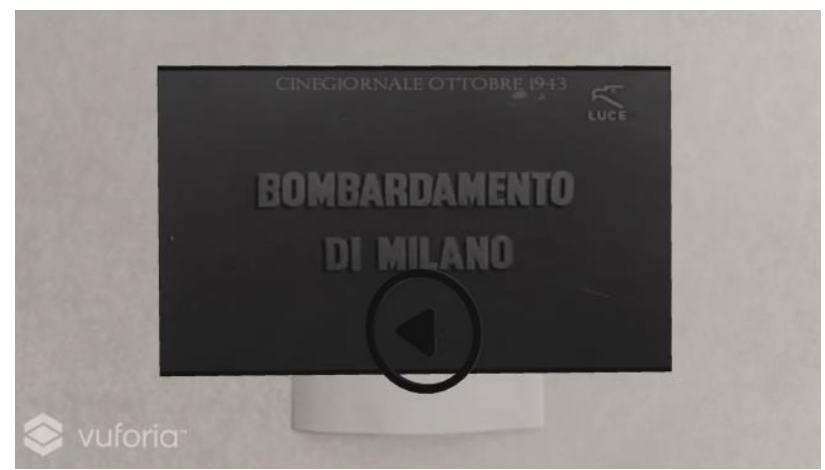

Figure 12. AR app created with Vuforia

Actually, the most recent AR applications tend to use as targets three-dimensional objects. In this case we have deliberately chosen to use two-dimensional targets since in the cloister there are no isolated 3D elements that can represent effective reference points. Another reason behind this choice is related to the need to create a target immediately recognizable by the user. Ultimately, as mentioned, VR simulation is both interactive and immersive (because it enables the user not only to modify elements of the environment around him but also to feel fully projected in the fictitious space). Instead the AR experience is strictly interactive, since the user has to interact with the real world around him (using the virtual buttons) in order to view the various virtual elements overlapped with the real place. The immersion, in the AR simulation, is guaranteed by the fact of being in the real Cloister of the Prior: this is the reason why this second experimentation will have no less impact than the VR one.

\section{CONCLUSION}

The project of digital survey, digital reconstruction and virtual and augmented fruition of the Cloister of the Prior in the convent of Santa Maria delle Grazie has set itself the goal of showing the extraordinary effectiveness of the AR and VR simulations as tools for communicating knowledge, transmitting historical memories and enhancing inaccessible architectural heritage. This experimentation is a starting point for future research on the use of techniques $\left(360^{\circ}\right.$ photos, projections of textures on the surfaces to be detected, etc.) that can overcome the difficulties and inaccuracies inherent in the survey of monochromatic surfaces without significant reference points (such as the plastered walls of the object of study). We also think to frame this experimentation within a larger project, which aims at a gradual reconstruction of the other rooms of the convent (starting from the Sacristy of Bramante and the Cloister of the Frogs, which are directly connected to the Cloister of the Prior). Finally, in this context, we want to deepen the research on the case study with the ultimate goal of creating a virtual reconstruction of the cloister in its original form, modified during the nineteenth-century intervention of Beltrami. It is a very demanding but at the same time a fascinating challenge, since it would make it possible to bring back to life a place that no longer exists and to recover, to study and to rearrange for the first time in a systematic way the few documents, images and projects that have survived to the destruction of the bombings.

\section{ACKNOWLEDGEMENTS}

We would especially like to thank Fra Adriano Cavallo of the Dominican Order for allowing the access to the Cloister of the Prior and its study.

\section{REFERENCES}

Aiello, D., Basso, A., Spena, M. T., D’Agostino, G., Montedoro, U., Galizia, M., Grasso, R., Santagati, C., 2019. The Virtual Batcave: a project for the safeguard of a Unesco WHL fragile ecosystem. Int. Arch. Photogramm. Remote Sens. Spatial Inf. Sci., XLII-2/W9, 17-24, https://doi.org/10.5194/isprs-archives-XLII-2-W9-17-2019.

Anderson, E., McLoughlin, L., Liarokapis, Peters, F., C., Petridis,P., and De Freitas, S., 2010. Developing Serious Games for Cultural Heritage: A State-of-the-Art Review. Virtual Reality 14(4).

ArtGlass, 2017. Bergamo: Viaggi d'acqua. https://www.artglass.it/progetti/ (last accessed March 2019).

Bepart, BASE, Terre di Mezzo, Bauer, PUSH and Fondazione Arrigo e Pia Pini, 2017. MAUA - Museo di Arte Urbana Aumentata. https://www.streetartfactory.eu/maua/ (last accessed March 2019).

Breuss-Schneeweis, P., 2016. "The speaking Celt": augmented reality avatars guide through a museum - case study. UbiComp '16 Proceedings of the 2016 ACM International Joint Conference on Pervasive and Ubiquitous Computing: Adjunct, pp. 1484-1491.

Caccin, A., Dell'Acqua, G. A., Bertelli, C., Bruschi, A., Bora, G., M., Ciati, B., Giordano, L., Gremmo, L., Mulazzani, G., Zanchi Pesenti, P., 1983. Santa Maria delle Grazie in Milano. Banca popolare di Milano, Milano. 
Candy, L., Ferguson, S. (Eds.), 2014. Interactive Experience in the Digital Age, Springer, New York.

Carrión-Ruiz, B., Blanco-Pons, S., Duong, M., Chartrand, J., Li, M., Prochnau, K., Fai, S., Lerma, J. L., 2019. Augmented experience to disseminate cultural heritage: House of Commons windows, Parliament Hill national historic site (Canada). Int. Arch. Photogramm. Remote Sens. Spatial Inf. Sci., XLII-2/W9, 243-247, https://doi.org/10.5194/isprs-archives-XLII-2-W9243-2019.

Curiosity Stream, Experius Vr, Reality Virtual, 2018. Nefertari: Journey to Eternity. https://www.oculus.com/experiences/rift/1491802884282318/ (last accessed March 2019).

Dhanda, A., Reina Ortiz, M., Weigert, A., Paladini, A., Min, A., Gyi, M., Su, S., Fai, S., and Santana Quintero, M., 2019. Recreating cultural heritage environments for VR using photogrammetry. Int. Arch. Photogramm. Remote Sens. Spatial Inf. Sci., XLII-2/W9, 305-310, https://doi.org/10.5194/isprsarchives-XLII-2-W9-305-2019.

DoSomethingGood, 2018. MoMAR - AR Gallery. https://momar.gallery/index.html (last accessed March 2019).

Gattico, G., 2004. Descrizione succinta e vera delle cose spettanti alla Chiesa e convento di Santa Maria delle Grazie e di Santa Maria della Rosa e suo luogo, et altre loro aderenze in Milano dell'Ordine de' Predicatori con due tavole in fine. Castello Sforzesco, Milano.

Liestøl, G., 2014. Along the Appian Way. Storytelling and Memory across Time and Space in Mobile Augmented Reality. EuroMed 2014, LNCS 8740, pp. 248-257.

Marani, P., Cecchi, R., Mulazzani, G., 1986. Il Cenacolo e Santa Maria delle Grazie. Mondadori Electa, Milano, pp.95.

Martelli, G., 1981. Il refettorio di Santa Maria delle Grazie in Milano e il restauro di Luca Beltrami nell'ultimo decennio dell'ottocento. Istituto Poligrafico e Zecca dello Stato, Roma.

Smithsonian Institution, 2015. Skin and Bones. https://itunes.apple.com/us/app/skin-

bones/id929733243?ls=1\&mt=8 (last accessed March 2019).

Palestini, C., Basso, A., 2017. The photogrammetric survey methodologies applied to low cost $3 \mathrm{~d}$ virtual exploration in multidisciplinary field. Int. Arch. Photogramm. Remote Sens. Spatial Inf. Sci., XLII-2/W8, 195-202.

Palma, V., Spallone, R., Vitali, M., 2019. Augmented Turin baroque atria: AR experiences for enhancing cultural heritage. Int. Arch. Photogramm. Remote Sens. Spatial Inf. Sci., XLII2/W9, 557-564, https://doi.org/10.5194/isprs-archives-XLII-2W9-557-2019.

Perfetti, L., Polari, C., Fassi, F., 2017. Fisheye photogrammetry: tests and methodologies for the survey of narrow spaces. Int. Arch. Photogramm. Remote Sens. Spatial Inf. Sci., XLII-2/W3, 573-580, https://doi.org/10.5194/isprs-archives-XLII-2-W3573-2017.
Perfetti, L., Polari, C.; Fassi, F., Troisi, S., Baiocchi, V., Del Pizzo, S., Gionnane, F., Barazzetti, L., Previtali, M., Roncoroni, F., 2018. Fisheye Photogrammetry to Survey Narrow Spaces in Architecture and a Hypogea Environment. In: Latest Developments in Reality-Based 3D Surveying and Modelling; Remondino, F., Georgopoulos, A., González-Aguilera, D., Agrafiotis, P., Eds.; MDPI: Basel, Switzerland, pp. 3-28.

Pietroni, E., 2013. Natural interaction in VR environments for cultural heritage: the virtual reconstruction of the RegoliniGalassi tomb in Cerveteri. Archeologia e Calcolatori, 24. pp. 231-247.

7reasons Medien GmbH, 2018. Carnuntum app. https://www.carnuntum.at/en/visitor-information/carnuntumapp (last accessed March 2019). 